\title{
EVALUATION OF RIPASA SCORING IN THE DIAGNOSIS OF ACUTE APPENDICITIS
}

\author{
Hafsa Salim Daber ${ }^{1}$, Srinath $S^{2}$
}

1Junior Resident, Department of General Surgery, Sri Siddhartha Medical College, Tumkur, Karnataka, India. 2Professor, Department of General Surgery, Sri Siddhartha Medical College, Tumkur, Karnataka, India.

\section{BACKGROUND}

ABSTRACT

Acute appendicitis is a commonly encountered surgical emergency and is often difficult to diagnose. The RIPASA appendicitis scoring system is easy and simple to apply and one of the most promising tool that can be obtained from a routine history and clinical examination. This present study aims to evaluate the usefulness of this scoring system in patients with a provisional diagnosis of acute appendicitis in a general hospital.

\section{MATERIALS AND METHODS}

This prospective study was conducted among 40 patients who presented with right iliac fossa pain in the Department of General Surgery at Sri Siddhartha Medical College and Research Institute, Tumkur between September 2016 and September 2018. Relevant history was taken, and clinical examinations and lab investigations were conducted. RIPASA and Modified ALVARADO score were applied to the patients.

\section{RESULTS}

The mean age of study population was 27.25 years and majority were males 29 (72.50\%). Clinical presentation by patients included pain in right iliac fossa 39 (97.50\%), migration of pain $34(85 \%)$, anorexia 37 (92.50\%). nausea and vomiting 39 $(97.50 \%)$ and fever $33(82.50 \%)$.The mean RIPASA score in the study population was 11 . The RIPASA score had sensitivity of $97.3 \%$ (95\% CI 92.08\%- 100\%) in predicting histopathology; the specificity of $66.7 \%$ (95\% CI 13.37\%- 100\%), diagnostic accuracy of $95 \%$ (95\% CI $88.25 \%-100 \%)$.

\section{CONCLUSIONS}

RIPASA score has a sensitivity of $97.3 \%$ and specificity of $66.7 \%$. The diagnostic accuracy OF RIPASA score was $95 \%$. Considering the high sensitivity and specificity, as compared to previous scoring systems and almost comparable sensitivity and specificity with ultrasonography, RIPASA score can be considered as a useful tool in making clinical decisions in resource poor settings.The RIPASA appendicitis scoring system is a promising tool in detecting appendicitis.

HOW TO CITE THIS ARTICLE: Daber HS, Srinath S. Evaluation of RIPASA scoring in the diagnosis of acute appendicitis. J. Evolution Med. Dent. Sci. 2019;8(13):977-981, DOI: 10.14260/jemds/2019/219

\section{BACKGROUND}

Acute appendicitis is an acute inflammation of the appendix and is one of the most common surgical emergencies making up $10 \%$ of all emergency abdominal surgeries. ${ }^{1}$ The mortality rates associated with acute appendicitis is reported to be $26 \%$ and has dropped to less than $1 \%$ due to early surgical intervention and antibiotics. Despite being a common problem, acute appendicitis remains a difficult diagnosis to establish, particularly among the young, the elderly and females of reproductive age.

Failure to diagnose early appendicitis converts acute appendicitis to perforated appendicitis to perforated appendicitis, a disease with potential complication including perforation and sepsis with its attendant morbidity and occasional mortality. ${ }^{2}$

The diagnosis particularly difficult among the young, the elderly and gynaecological inflammatory conditions.

'Financial or Other Competing Interest': None.

Submission 25-02-2019, Peer Review 20-03-2019,

Acceptance 23-03-2019, Published 01-04-2019.

Corresponding Author:

Dr. Hafsa Salim Daber,

W/o. Dr. Daber Pareed,

Kaithavalop House,

Downhill, P. O.,

Malappuram,

Kerala,

E-mail:dr.hafsadaber@gmail.com

DOI: $10.14260 /$ jemds/2019/219

\section{(c) (i) () $९$}

This is particularly true in the early stages of the disease. A negative appendicectomy rate of $20-44 \%$ is not unusual in the surgical literature, and many surgeons would accept a negative appendectomy rate of up to $30 \%$ as inevitable. Further ahost of other genitourinary and gynaecological inflammatory conditions can present with signs and symptoms that are similar to those of acute appendicitis. ${ }^{3}$

The exact diagnosis of the disease can be made only after surgery and pathological examination of the surgical specimen. Diagnostic accuracy can be further improved through the use of ultrasonography or computed tomography imaging. However, these modalities are costly and are not readily available.

Several scoring systems, such as the Alvarado and modified Alvarado scoring system, have been introduced since 1986 to help with the clinical decision-making process in achieving an accurate diagnosis of acute appendicitis in the fastest and cheapest way. ${ }^{2,4}$ However, these two scoring systems were created in the West, and when applied in different environments, such as the Middle East and Asia, the sensitivity and specificity levels achieved were very low.5,6 Khan et al. ${ }^{6}$ applied the Alvarado scoring system in an Asian population and only achieved a sensitivity and specificity of $59 \%$ and $23 \%$, respectively, with a negative appendicectomy rate of $15.6 \%$. Another study by Al-Hashemy et al. 5 in 2004 using the modified Alvarado scoring system in a Middle Eastern population reported similarly low sensitivity of $53.8 \%$ and a specificity of $80 \%{ }^{4}$ suggesting a definite ethnic difference with regard to the Alvarado score. ${ }^{7}$ Both the 
Alvarado and modified Alvarado scores lack parameters that have been shown to be important determinants in the diagnosis of acute appendicitis, such as age, gender and the duration of symptoms.

Raja Isteri Pengiran Anak Saleha Appendicitis (RIPASA) is a new scoring system. RIPASA has been developed for a better diagnosis of acute appendicitis; this score includes 14 clinical parameters, which have higher sensitivity, specificity, and diagnostic accuracy than Alvarado scoring, especially in the Asian population.This new appendicitis scoring system is easy and simple to apply as the majority of the parameters can be obtained from a routine history and clinical examination.The RIPASA score is sensitive and specific for the diagnosis of acute appendicitis in a western population by Malik et al. ${ }^{8}$ Even in Indian population recently Singh, A., et $\mathrm{al}^{9}$ have conducted a study to determine the validation of RIPASA score in diagnosis of acute appendicitis and histopathological correlation.There were limited studies in Indian settings to evaluate the usefulness of this scoring system in patients with a provisional diagnosis of acute appendicitis.Hence the present study aims to validate the RIPASA scoring system in the diagnosis of acute appendicitis among patients presenting with right iliac fossa pain.

\section{MATERIALS AND METHODS}

This was a prospective observational study conducted among 40 patients presenting with RIF pain in the Department of general surgery at Sri Siddhartha Medical College, Tumkur between October 2016 and April 2018 for a period of 18 months. The sample size was calculated assuming expected proportion of people with histopathologically confirmed appendicitis as $89.3 \%$ as per the study by Nanjundaiah $\mathrm{N}$ et al. ${ }^{10} \mathrm{~A} 7 \%$ precision for sensitivity and 30\% precision for specificity calculation was considered. An expected sensitivity of $96.2 \%$ and expected specificity of $90.5 \%$, were hypothesized as per the same reference study. The sample size was calculated using Bruder's formula. To account for a loss to follow up and non-participation rate of $5 \%$ another 2 subjects were added and the final study had included 40 subjects.

All the eligible patients presenting with right iliac fossa pain were recruited into the study consecutively till the sample size is reached. Exclusion criteria were patients with non-RIF pain, admitted for reasons other than RIF, received antibiotic treatment in the last 48 hours for the pain, not willing for surgery, pregnancy, less than the age of 12 years, with appendicular mass or abscess. Ethical clearance was obtained from the institution review board before the start of study. Informed consent was collected from the participants and all the relevant parameters were documented in a structured study proforma. A detailed case history was taken. Examination included RIF tenderness, RIF guarding, rebound tenderness, Rovsing's sign and fever. Laboratory investigations included $\mathrm{CBC}$, routine urine test. The RIPASA score was computed as per guidelines. RIPASA score of $<7.5$ was considered as cut off to label a person as high or low probability of appendicitis. Operative notes and histopathology reports were reviewed and correlated with the RIPASA score. If the patientwas not operated and discharged, the negative appendicitis was confirmed during follow up visit or by a phone call to see if the patient has got operated elsewhere.

\section{Statistical Analysis}

RIPASA score was considered as the screening test. Histopathology was considered as primary outcome variables. Age, gender, comorbidities etc., were considered as other variables of interest for analysis. Descriptive analysis was carried out by mean and standard deviation for quantitative variables, frequency and proportion for categorical variables. The association between categorical explanatory variables and the quantitative outcome was assessed by comparing the mean values. The mean differences along with their 95\% CI were presented. Independent sample t-test/ was used to assess statistical significance. The sensitivity, specificity and predictive values of the RIPASA score categories were calculated against the gold standard (Histopathology examination) $\mathrm{P}$ value $<0.05$ was considered statistically significant. IBM SPSS version 22 was used for statistical analysis. ${ }^{11}$

\section{RESULTS}

A total of 40 subjects were included in the final study, majority were males $(72.5 \%)$ with a mean age of $27.25 \pm$ 10.92 (Table 1)

\begin{tabular}{|c|c|}
\hline Demographic Characteristic & Mean \pm SD \\
\hline Age & $27.25 \pm 10.92$ \\
\hline Gender & $\mathrm{N}(\%)$ \\
Male & $29(72.5)$ \\
Female & $11(27.5)$ \\
\hline
\end{tabular}

Table 1. Demographic Characteristic of Study Population $(n=40)$

Table 2 provides the baseline characteristic of study population. Majority of the study population 39 (97.50\%) had right iliac fossa pain. Most common symptoms were anorexia (92.5), nausea and vomiting (97.5\%), fever (82.5\%).

\begin{tabular}{|c|c|}
\hline Baseline Characteristic & n (\%) \\
\hline Right Iliac Fossa Pain & $39(97.5)$ \\
\hline Migration of Pain & $34(85)$ \\
\hline Anorexia & $37(92.5)$ \\
\hline Nausea and Vomiting & $39(97.5)$ \\
\hline Fever & $33(82.5)$ \\
\hline Duration of Symptoms < 48 (Hours) & $17(42.5)$ \\
\hline Duration of Symptoms $>48$ (Hours) & $23(57.5)$ \\
\hline RIF Tenderness & $36(90)$ \\
\hline Rebound Tenderness & $32(80)$ \\
\hline Guarding & $13(32.5)$ \\
\hline Rovsing's Sign & $18(45)$ \\
\hline WBC & $39(97.5)$ \\
\hline Negative Urine Analysis & $39(97.5)$ \\
\hline Positive Ultra Sound Sonography & $36(90)$ \\
\hline Positive Histopathology & $37(92.5)$ \\
\hline \multicolumn{2}{|c|}{$\begin{array}{l}\text { Table 2. Baseline Characteristics of Study Population } \\
\qquad(n=40)\end{array}$} \\
\hline
\end{tabular}

The mean RIPASA score in the study population was 11.1 \pm 1.76 with the minimum 4.50 and maximum $14.50(95 \% \mathrm{CI}$ 10.54-11.66). Majority of the study population (60\%) were with a $7.5-11.5$ range of RIPASA score, $37.50 \%$ of the study population scored >11.5 RIPASA score and only $2.50 \%$ scored $<7.5$ RIPASA score. Table 3 shows the association of various parameters with RIPASA score. A significant difference was found between mean RIPASA score with 
nausea and vomiting, RIF tenderness, Rovsing's sign raised WBC count.

\begin{tabular}{|c|c|c|c|}
\hline Parameter & $\begin{array}{c}\text { RIPASA Score } \\
\text { Mean } \pm \text { SD }\end{array}$ & $\begin{array}{c}\text { Mean } \\
\text { Difference } \\
(95 \% \mathrm{CI})\end{array}$ & \begin{tabular}{|c}
$\mathbf{p}$ \\
Value
\end{tabular} \\
\hline $\begin{array}{l}\text { Gender } \\
\text { Male } \\
\text { Female }\end{array}$ & $\begin{array}{l}11.12 \pm 1.84 \\
11.05 \pm 1.62\end{array}$ & $0.08(-1.20-1.38)$ & 0.906 \\
\hline \begin{tabular}{|c|} 
Age Group \\
Up to 40 years \\
40 years and above
\end{tabular} & $\begin{array}{c}11.22 \pm 1.42 \\
10 \pm 3.87\end{array}$ & $1.22(-0.64-3.08)$ & 0.191 \\
\hline $\begin{array}{c}\text { Right Iliac Fossa } \\
\text { Pain } \\
\text { Yes } \\
\text { No } \\
\end{array}$ & $\begin{array}{c}11.12 \pm 1.78 \\
10.5 \pm 0\end{array}$ & $0.62(-3.03-4.26)$ & 0.735 \\
\hline \begin{tabular}{|c|} 
Migration of Pain \\
Yes \\
No
\end{tabular} & $\begin{array}{l}11.15 \pm 1.85 \\
10.83 \pm 1.17\end{array}$ & $0.31(-1.28-1.91)$ & 0.692 \\
\hline $\begin{array}{c}\text { Anorexia } \\
\text { Yes } \\
\text { No }\end{array}$ & $\begin{array}{c}11.24 \pm 1.42 \\
9.33 \pm 4.37\end{array}$ & $1.91(-0.16-3.98)$ & 0.070 \\
\hline $\begin{array}{c}\text { Nausea and } \\
\text { Vomiting } \\
\text { Yes } \\
\text { No }\end{array}$ & $\begin{array}{c}11.27 \pm 1.41 \\
4.5 \pm 0\end{array}$ & $6.77(3.87-9.67)$ & $<0.001$ \\
\hline $\begin{array}{c}\text { Duration of } \\
\text { Symptoms }<48 \\
\text { Hours } \\
\text { Yes } \\
\text { No }\end{array}$ & $\begin{array}{l}10.85 \pm 1.37 \\
11.28 \pm 2.01\end{array}$ & $-0.43(-1.57-0.72)$ & 0.452 \\
\hline $\begin{array}{c}\text { Duration of } \\
\text { Symptoms }>\mathbf{4 8} \\
\text { Hours } \\
\text { Yes } \\
\text { No }\end{array}$ & $\begin{array}{c}11.17 \pm 2.15 \\
11 \pm 1.09\end{array}$ & $0.17(-0.98-1.33)$ & 0.762 \\
\hline $\begin{array}{c}\text { RIF Tenderness } \\
\text { Yes } \\
\text { No } \\
\end{array}$ & $\begin{array}{c}11.29 \pm 1.47 \\
9.38 \pm 3.28 \\
\end{array}$ & $1.92(0.12-3.71)$ & 0.037 \\
\hline $\begin{array}{c}\text { Rebound } \\
\text { Tenderness } \\
\text { Yes } \\
\text { No }\end{array}$ & $\begin{array}{c}11.3 \pm 1.45 \\
10.31 \pm 2.66\end{array}$ & $0.98(-0.40-2.37)$ & 0.159 \\
\hline $\begin{array}{c}\text { Guarding } \\
\text { Yes } \\
\text { No }\end{array}$ & $\begin{array}{l}11.54 \pm 1.51 \\
10.89 \pm 1.86\end{array}$ & $0.65(-0.55-1.85)$ & 0.280 \\
\hline $\begin{array}{c}\text { Rovsing's Sign } \\
\text { Yes } \\
\text { No } \\
\end{array}$ & $\begin{array}{c}12.08 \pm 1.19 \\
10.3 \pm 1.76\end{array}$ & $1.79(0.80-2.77)$ & $<0.001$ \\
\hline $\begin{array}{l}\text { Fever } \\
\text { Yes } \\
\text { No }\end{array}$ & $\begin{array}{l}11.61 \pm 1.2 \\
8.71 \pm 2.08\end{array}$ & $2.89(1.73-4.05)$ & $<0.001$ \\
\hline $\begin{array}{c}\text { Raised White Cell } \\
\text { Count } \\
\text { Yes } \\
\text { No }\end{array}$ & $\begin{array}{c}11.27 \pm 1.41 \\
4.5 \pm 0.12\end{array}$ & 6.77 (3.87- 9.67) & $<0.001$ \\
\hline $\begin{array}{c}\text { Negative Urine } \\
\text { Analysis } \\
\text { Yes } \\
\text { No }\end{array}$ & $\begin{array}{c}11.19 \pm 1.68 \\
7.5 \pm 0.27\end{array}$ & $3.69(0.25-7.14)$ & .036 \\
\hline
\end{tabular}

Among the people with positive Histopathology 36 (97.29\%) were with high (>=7.5) RIPASA score and only 1 $(2.702 \%)$ was with low $(<7.5)$ RIPASA score. The difference in the proportion of high and low RIPASA scores between histopathology was statistically significant ( $\mathrm{P}$ value $<0.001)$.

\begin{tabular}{|c|c|c|}
\hline Parameter & RIPASA score & Ultrasound \\
\hline Sensitivity & $97.3 \%$ & $94.6 \%$ \\
\hline Specificity & $66.7 \%$ & $66.7 \%$ \\
\hline False Positive Rate & $33.3 \%$ & $33.3 \%$ \\
\hline False Negative Rate & $2.7 \%$ & $5.4 \%$ \\
\hline Positive Predictive Value & $97.3 \%$ & $97.2 \%$ \\
\hline Negative Predictive Value & $66.7 \%$ & $50.0 \%$ \\
\hline Diagnostic Accuracy & $95.0 \%$ & $92.5 \%$ \\
\hline \multicolumn{2}{|c|}{$\begin{array}{r}\text { Table 4. Predictive Validity of RIPASA Score and } \\
\text { Ultrasound as Compared to HPE (N=40) }\end{array}$} \\
\hline
\end{tabular}

The RIPASA score had sensitivity of $97.3 \%$ and specificity of $66.7 \%$ in predicting acute appendicitis. Whereas ultrasound had $94.6 \%$ and $66.7 \%$ sensitivity and specificity in predicting acute appendicitis compared to histopathology. This showed that both RIPASA score and ultrasound can be used for predicting appendicitis among patients with the highest diagnostic accuracy for RIPASA score (95\%).

\section{DISCUSSION}

Preoperative diagnosis of acute appendicitis is one of the great enigmas of surgery so much so that doing negative appendectomies is an acceptable term and a high percentage of negative appendectomies (20\%) is regarded as reasonable. 12 The current prospective study evaluated 40 study participants to validate the RIPASA score in the diagnosis of acute appendicitis.

The mean age of the study population was 27.25 years. The proportion of males was $(72.50 \%)$ significantly higher than females (27.50\%). The male to female ratio was 2.63:1. Similar study settings were seen in Singh, A., et al ${ }^{9}$ study where the mean age of the participants was 27.55 years. But a study by Malik, M. U., et al ${ }^{8}$ showed that mean age of the study population was 22.7 years, which is slightly lower than the current study. The proportion of male and females was also almost equal ( $51 \%$ Vs $49 \%$ ).

In our study, the proportion of participants with right iliac fossa pain were $97.50 \%$. Migration of pain was seen in $85 \%$ of the participants. Singh, A., et $\mathrm{al}^{9}$ have reported a slightly lower proportion (92\%) of participants with right iliac fossa pain. But in a study by Srikantaiah, H. et al, 13 all the study participants, had RIF pain and migration of pain was seen in $59 \%$ of the participants. In Naresh, G. et al.14 Study also all the 100 participants had RIF pain, but the migration of pain was seen in $48 \%$ of the cases. In the present study, $92.50 \%$ of the study population had Anorexia. The proportion of participants with nausea and vomiting was $97.50 \%$. Feverwas found in $82.50 \%$ of the study participants. Naresh, G. et al. 14 reported that $34 \%$ gave a positive history of anorexia while 47 patients (47\%) gave a history of nausea and vomiting and this proportions were 29\% and 33\% respectively Srikantaiah, H. et al. ${ }^{13}$

In our study, $42.50 \%$ of the study participants had Duration of symptoms $<48$ hours whereas $57.50 \%$ people had Duration of symptoms $>48$ hours. Similar to our study in Naresh, G., et al. ${ }^{14}$ study among the 100 patients, 55 patients $(55 \%)$ presented with a history lasting less than two days (48 hrs) while 45 patients (45\%) presented with a history lasting more than 2 days ( $>48 \mathrm{hrs}$ ). A duration of symptoms of $<48$ hours showed a higher probability of acute appendicitis and 
was scored with 1.0 point, while duration of symptoms $>48$ hours was scored with 0.5 points.

In our study, $90 \%$ of the participants had RIF tenderness. $80 \%$ of them had shown Rebound tenderness. $32.50 \%$ of the study participants had Guarding, and Rovsing's sign was seen on $45 \%$ of cases. In Naresh, G. et al.14 study all the participants RIF tenderness. Our study findings were comparable with Singh, A., et $\mathrm{al}^{9}$ where RIF tenderness was observed in $84 \%$ of cases, $79 \%$ of the cases had Rebound tenderness. The proportions of Guarding and Rovsing's sign were $17 \%$ and $30 \%$ respectively. In the current study, $97.50 \%$ of the study population had raised white cell count whereas $97.5 \%$ showed negative Urine analysis. Like our study Srikantaiah, H. et al 13 92\% of patients with appendicitis had raised TC, but urine analysis was positive only in $15 \%$ of cases. In the current study, the mean RIPASA score in the study population was 11.1 with the minimum 4.50 and maximum 14.50. Majority of the study population $(60 \%)$ were with a 7.5-11.5 range of RIPASA score, $37.50 \%$ of the study population scored $>11.5$ RIPASA score and only $2.50 \%$ scored $<7.5$ RIPASA score. Singh et al ${ }^{9}$ have shown that the RIPASA score of $<5$ is observed in 11 patients (M, 5; F, 6), 5-7 in 36 patients (M, 19; F, 17), 7.5-11.5 in 137 (M, 95; F, 42), > 12 in $16(\mathrm{M}, 9 ; \mathrm{F}, 7)$.

In the current study, $90 \%$ of the study population showed positive results in Ultrasound sonography and the proportion of cases with positive histopathology report was $92.50 \%$.

The current study showed a significant difference in positive histopathological findings and mean RIPASA score. Similarly, in a study by Singh, A., et al ${ }^{9}$ shown that among 178 operated cases, histopathology report of 146 showed changes consistent with acute appendicitis and among these are the following: 140 had a RIPASA score of $>7.5$ (True positive); six patients had a score of $<7.5$ but histopathology was suggestive of acute appendicitis; 32 patients had normal appendix on histopathological examination and out of them, 13 had score of $>7.5$ (false positive) and 19 had a score of $<7.5$ (true negative) In the current study the RIPASA score had sensitivity of $97.3 \% \quad(95 \%$ CI $92.08 \%-100 \%)$ in predicting histopathology and specificity of $66.7 \%$, the false Positive rate was $33.3 \%$, the False negative rate was $2.7 \%$ the positive predictive value was $97.3 \%$, the negative predictive value was $66.7 \%$. The final diagnostic accuracy was $95 \%$. Similar findings were reported by Malik et al ${ }^{8}$ where Twentytwo had a false positive, 19 had a false negative and 51 had a true negative resulting in a sensitivity of $85.93 \%$, specificity of $69.86 \%$, PPV of $84.06 \%$, NPV of $72.86 \%$ and diagnostic accuracy of $80.01 \%$. Our study findings also comparable with Singh el $\mathrm{al}^{9}$ where sensitivity of the RIPASA score was $95.89 \%$, specificity $75.92 \%$, positive predictive value $91.50 \%$, and negative predictive value $87.23 \%$ with diagnostic accuracy of $90.5 \%$. Our results are comparable with previous studied on RIPASA score like Chee Fui Chong et al. ${ }^{15,16}$ and (Sensitivity of $97.5 \%$, specificity of $81.8 \%$, PPV of $86.5 \%$, NPV of $96.4 \%$, and a diagnostic accuracy of $91.8 \%$ ).Butt, M. Q., et al ${ }^{17}$ have shown that Sensitivity of RIPASA score was $96.7 \%$, specificity $93.0 \%$, diagnostic accuracy was $95.1 \%$, positive predictive value was $94.8 \%$ and negative predictive value was $95.54 \%$.

But these results should be considered under studies limitations. First and foremost, owing to the cross-sectional nature of the study the observed association cannot be interpreted as causal inferences. Second, we had used nonprobability sampling technique which is not a true representation of the general population. The generalizability of study findings to other settings may be very limited, as the study was conducted in a single centre and the population evaluated represents a limited geographical locality. There is a need to conduct further large-scale studies on the subject to further demonstrate the utility of RIPASA score in different settings.

\section{CONCLUSION}

RIPASA score has a sensitivity of $97.3 \%$ and specificity of $66.7 \%$. The diagnostic accuracy OF RIPASA score was $95 \%$. Considering the high sensitivity and specificity, as compared to previous scoring systems and almost comparable sensitivity and specificity with ultrasonography, RIPASA score can be considered as a useful tool in making clinical decisions in resource poor settings. The RIPASA appendicitis scoring system is a promising tool in detecting appendicitis.

\section{REFERENCES}

[1] Pal KM, Khan A. Appendicitis: a continuing challenge. J Pak Med Assoc 1998;48(7):189-92.

[2] Kalan M, Talbot D, Cunliffe WJ, et al. Evaluation of the modified Alvarado score in the diagnosis of acute appendicitis: a prospective study. Ann R Coll Surg Engl 1994;76(6):418-9.

[3] Gilmore OJ, Browett JP, Griffin PH, et al. Appendicitis and mimicking conditions. A prospective study. Lancet 1975;306(7932):421-4.

[4] Alvarado A. A practical score for the early diagnosis of acute appendicitis. Ann Emerg Med 1986;15(5):55764.

[5] Al-Hashemy AM, Seleem MI. Appraisal of the modified Alvarado Score for acute appendicitis in adults. Saudi Med J 2004;25(9):1229-31.

[6] Khan I, Ur Rehman A. Application of Alvarado scoring system in diagnosis of acute appendicitis. J Ayub Med Coll Abbottabad 2005;17(3):41-4.

[7] Jang SO, Kim BS, Moon DJ. Application of Alvarado score in patients with suspected appendicitis. Korean J Gastroenterol 2008;52(1):27-31.

[8] Malik MU, Connelly TM, Awan F, et al. The RIPASA score is sensitive and specific for the diagnosis of acute appendicitis in a western population. Int J Colorectal Dis 2017;32(4):491-7.

[9] Singh A, Parihar US, Kumawat G, et al. To determine validation of RIPASA score in diagnosis of suspected acute appendicitis and histopathological correlation with applicability to Indian population: a single institute study. Indian J Surg 2018;80(2):113-7.

[10] Nanjundaiah N, Mohammed A, Shanbhag V, et al. A comparative study of RIPASA Score and Alvarado Score in the diagnosis of acute appendicitis. J Clin Diagn Res 2014;8(11):NC03-NC5.

[11] IBM Corp. IBM SPSS Statistics for Windows, Version 22.0. Armonk, NY: IBM Corp. Released 2013.

[12] Toorenvliet BR, Wiersma F, Bakker RF, et al. Routine ultrasound and limited computed tomography for the diagnosis of acute appendicitis. World J Surg 2010;34(10):2278-85. 
[13] Srikantaiah HC, Arvind NK. Validation of RIPASA scoring system for the diagnosis of acute appendicitis. Journal of Evolution of Medical and Dental Sciences 2015;4(100):16533-48.

[14] Naresh G, Reddy MV, Inamdar P. Evaluation of acute appendicitis according to RIPASA scoring system. Indian J Appl Res 2018;8(9).

[15] Chong CF, Adi MI, Thien A, et al. Development of the RIPASA score: a new appendicitis scoring system for the diagnosis of acute appendicitis. Singapore Med J 2010;51(3):220-5.
[16] Chong C, Thien A, Mackie AJ, et al. Comparison of RIPASA and Alvarado scores for the diagnosis of acute appendicitis. Singapore Med J 2011;52(5):340-5.

[17] Butt MQ, Chatha SS, Ghumman AQ, et al. RIPASA score: a new diagnostic score for diagnosis of acute appendicitis. J Coll Physicians Surg Pak 2014;24(12):894-7. 